\title{
Review Skripsi
}

\begin{tabular}{|c|c|}
\hline Judul Penelitian & $\begin{array}{l}\text { PERAN HUMAS LEMBAGA NEGARA DALAM MENJAGA } \\
\text { REPUTASI ORGANISASI (STUDI PADA PERAN HUMAS DPR } \\
\text { RI DALAM MENJAGA REPUTASI KINERJA ANGGOTA DPR } \\
\text { RI) }\end{array}$ \\
\hline Nama Peneliti & Tika Oktavianingsih \\
\hline Universitas & Universitas Indonesia \\
\hline Fakultas & Ilmu Sosial dan Ilmu Politik \\
\hline Tahun & 2012 \\
\hline Rumusan Masalah & $\begin{array}{l}\text { 1. Bagaimana peran Humas DPR RI dalam menjaga reputasi kinerja } \\
\text { anggota DPR RI? } \\
\text { 2. Apa saja hambatan-hambatan yang dihadapi Humas DPR dalam } \\
\text { menjaga reputasi kinerja anggota DPR? }\end{array}$ \\
\hline Tujuan Penelitian & $\begin{array}{l}\text { 1. mengidentifikasi peran Humas DPR RI dalam menjaga reputasi } \\
\text { kinerja anggota DPR RI. } \\
\text { 2. Mengidentifikasi hambatan-hambatan apa saja yang dihadapi } \\
\text { humas DPR dalam menjaga reputasi kinerja anggota dewan. }\end{array}$ \\
\hline Teori dan Konsep & $\begin{array}{l}\text { 1. Hubungan Masyarakat } \\
\text { 2. Fungsi Hubungan Masyarakat } \\
\text { 3. Tugas Hubungan Masyarakat } \\
\text { 4. Peran Hubungan Masyarakat } \\
\text { 5. Hubungan Masyarakat Pemerintah } \\
\text { 6. Tugas Hubungan Masyarakat Pemerintah } \\
\text { 7. Peran Hubungan Masyarakat Pemerintah } \\
\text { 8. Tahapan model perkembangan komunikasi dan praktek humas } \\
\text { 9. Rencana Strategis Humas } \\
\text { 10. Reputasi }\end{array}$ \\
\hline Metode Penelitian & Pendekatan Kualitatif \\
\hline Sifat Penelitian & Sifat Deskriptif \\
\hline Strategi Penelitian & Studi Kasus \\
\hline $\begin{array}{l}\text { Metode } \\
\text { Pengumpulan Data }\end{array}$ & $\begin{array}{l}\text { Data Primer : In-depth interview atau wawancara } \\
\text { Data Sekunder : Observasi dan Studi Dokumentasi }\end{array}$ \\
\hline $\begin{array}{ll}\text { Teknik } & \text { Memilih } \\
\text { Informan } & \end{array}$ & Pengambilan data secara purposif \\
\hline $\begin{array}{l}\text { Metode Analisis } \\
\text { Data }\end{array}$ & Analisis Tematik \\
\hline Kualitas Penelitian & Triangulasi Data \\
\hline Kesimpulan & $\begin{array}{l}\text { Dalam menjaga reputasi kinerja anggota dewan, Humas DPR RI } \\
\text { telah melakukan berbagai strategi komunikasi untuk } \\
\text { mempublikasikan kinerja anggota dewan, diantaranya : penerbitan } \\
\text { majalah dan bulletin Parlementaria, penyiaran tv parlemen, Blocking } \\
\text { rubric di TVRI dan RRI, publikasi melalui website DPR, } \\
\text { mengadakan konferensi pers setiap minggu. Dan dalam } \\
\text { melaksanakan tugasnya humas mengalami hambatan-hambatan, } \\
\text { yaitu : tidak adanya komunikasi antara anggota DPR dengan } \\
\text { lembaga sehingga mengakibatkan tidak adanya koordinasi antara } \\
\text { lembaga dan anggota DPR dalam menyusun dan mengembangkan } \\
\text { pesan untuk dipublikasi kepada publik. Media di Indonesia memiliki }\end{array}$ \\
\hline
\end{tabular}




\begin{tabular}{|l|l|}
\hline & $\begin{array}{l}\text { kepentingan-kepentingan tertentu dan kurangnya hubungan baik } \\
\text { humas dengan media atau (media relations) yang masih rendah. Dan } \\
\text { struktur humas DPR RI secara kelembagaan masih jauh dari strategis }\end{array}$ \\
\hline Saran & $\begin{array}{l}\text { Konsep humas lembaga negara khususnya lembaga legislatif harus } \\
\text { diterapkan. Harus ada komunikasi antara anggota dewan dengan } \\
\text { lembaga DPR atau dalam hal ini humas sehingga dapat menciptakan } \\
\text { pesan yang akan disampaikan ke publik. }\end{array}$ \\
\hline
\end{tabular}

\begin{tabular}{|c|c|}
\hline Judul Penelitian & $\begin{array}{l}\text { PERAN HUBUNGAN MASYARAKAT (HUMAS) MPR RI } \\
\text { DALAM MENSOSIALISASIKAN EMPAT PILAR BANGSA } \\
\text { TAHUN } 2014\end{array}$ \\
\hline Nama Penelitian & Mochammad Kahfi \\
\hline Universitas & Universitas Islam Negeri Syarif Hidayatullah Jakarta \\
\hline Fakultas & Dakwah dan Ilmu Komunikasi \\
\hline Tahun & 2014 \\
\hline Rumusan Masalah & $\begin{array}{l}\text { 1. Bagaimana peran Humas MPR RI dalam mensosialisasikan Empat } \\
\text { Pilar Bangsa? } \\
\text { 2. Apa kegiatan Humas MPR RI dalam mensosialisasikan Empat } \\
\text { Pilar Bangsa? }\end{array}$ \\
\hline Tujuan Penelitian & $\begin{array}{l}\text { a. tujuan umum } \\
\text { untuk mengetahui sejauh mana Humas MPR RI membuat formula } \\
\text { serta langkah-langkah yang tepat untuk lebih bisa mensosialisasikan } \\
\text { empat pilar bangsa untuk menanamkan rasa nasionalis sebagaimana } \\
\text { yang diharapkan. } \\
\text { b. tujuan khusus } \\
\text { 1. untuk mengetahui peran Humas MPR RI dalam mensosialisasikan } \\
\text { Empat Pilar Bangsa dalam membangun rasa nasionalis berbangsa } \\
\text { dan bernegara. } \\
\text { 2. untuk mengetahui aktifitas dan kegiatan Humas MPR RI dalam } \\
\text { upaya mensosialisasikan Empat Pilar bangsa. }\end{array}$ \\
\hline $\begin{array}{l}\text { Metodologi } \\
\text { Penelitian }\end{array}$ & Kualitatif dengan metode deskriptif analisis \\
\hline Subjek Penelitian & Humas MPR RI \\
\hline Objek Penelitian & $\begin{array}{l}\text { Peranan Humas MPR RI dalam mensosialisasikan Empat Pilar } \\
\text { Bangsa. }\end{array}$ \\
\hline $\begin{array}{l}\text { Teknik Pengumpulan } \\
\text { Data }\end{array}$ & $\begin{array}{l}\text { 1. Observasi } \\
\text { 2. Dokumentasi } \\
\text { 3. Wawancara }\end{array}$ \\
\hline Teori dan Konsep & $\begin{array}{l}\text { 1. Peranan } \\
\text { 2. Humas } \\
\text { a. Pengertian Humas } \\
\text { b. Fungsi Humas } \\
\text { 3. Macam-macam Humas } \\
\text { a. Humas Pemerintahan } \\
\text { b. Humas Perusahaan } \\
\text { c. Humas Non Goverment Organization (Third sector) } \\
\text { 4. Peran Humas }\end{array}$ \\
\hline
\end{tabular}




\begin{tabular}{|l|l|}
\hline & $\begin{array}{l}\text { 5. Kegiatan Humas } \\
\text { 6. Sosialisasi } \\
\text { a. Definisi Sosialisasi } \\
\text { b. Jenis Sosialisasi }\end{array}$ \\
\hline Kesimpulan & $\begin{array}{l}\text { Perkembangan Empat Pilar Bangsa di Indonesia tidak lepas dari } \\
\text { peran serta universitas-universitas dan kalangannya dalam membuat } \\
\text { acara sosialisasi yang nyaman dan kondusif. Perlu adanya } \\
\text { pembinaan terhadap seluruh penyelenggara negara agar rasa } \\
\text { nasionalisme didalam diri terus ditularkan keseluruh lapisan } \\
\text { masyarakat. }\end{array}$ \\
\hline Saran & $\begin{array}{l}\text { 1. Peran Humas MPR RI belum dimanfaatkan secara optimal dan } \\
\text { strategis. Dapat dilihat dari kasus-kasus tertentu yang dialami MPR } \\
\text { RI dimana sering terjadi permasalahan-permasalahan opini publik } \\
\text { terpublikasikan secara tidak teroganisirdan terkoordinasi. } \\
\text { 2. Biro Humas MPR RI masih sangat sulit untuk menjalankan fungsi } \\
\text { politik kehumasan yang sebenarnya. }\end{array}$ \\
\hline
\end{tabular}

\begin{tabular}{|c|c|}
\hline Judul Penelitian & $\begin{array}{l}\text { Peran Humas Pemerintah Daerah Dalam Media Internal } \\
\text { (Studi deskriptif Kualitatif pada Buletin Jogjawara pemerintah } \\
\text { daerah provinsi daerah istimewa Yogyakarta) }\end{array}$ \\
\hline Nama Peneliti & Isti Puput Susanti \\
\hline Universitas & Universitas Islam Negeri Yogyakarta \\
\hline Fakultas & Ilmu Sosial Dam Humaniora \\
\hline Tahun & 2012 \\
\hline Rumusan Masalah & $\begin{array}{l}\text { 1. Bagaimana peran Humas Pemerintah Daerah Provinsi Daerah } \\
\text { Istimewa Yogyakarta dalam media internal pada buletin Jogjawara? }\end{array}$ \\
\hline Tujuan Penelitian & $\begin{array}{l}\text { 1. Menemukan peran Humas Pemerintah Daerag Provinsi Daerah } \\
\text { Istimewa Yogyakarta dalam media internal pada buletin Jogjawara. }\end{array}$ \\
\hline Landasan Teori & $\begin{array}{l}\text { 1. Peran } \\
\text { 2. Hubungan Masyarakat (Humas) } \\
\text { 2.1 Humas Instansi Pemerintah } \\
\text { 2.2 Peran Humas } \\
\text { 3. Media } \\
\text { 3.1 Media Internal } \\
\end{array}$ \\
\hline $\begin{array}{l}\text { Metodologi } \\
\text { Penelitian }\end{array}$ & Penelitian Kualitatif \\
\hline Subjek Penelitian & Humas Pemerintah Daerah Provinsi Daerah Istimewa Yogyakarta. \\
\hline Objek Penelitian & $\begin{array}{l}\text { Peran Humas Pemerintah Daerah Provinsi Daerah Istimewa } \\
\text { Yogyakarta. }\end{array}$ \\
\hline Ssumber Data & $\begin{array}{l}\text { 1. Humas Pemerintah Daerah Provinsi Daerah Istimewa Yogyakarta. } \\
\text { 2. Data yang bersumber dari dokumen, laporan, buletin dan arsip } \\
\text { yang mendukung sebagai bahan dalam penelitian. }\end{array}$ \\
\hline $\begin{array}{l}\text { Teknik Pengumpulan } \\
\text { Data }\end{array}$ & $\begin{array}{l}\text { 1. Wawancara mendalam ( in depth interview) } \\
\text { 2. Dokumentasi }\end{array}$ \\
\hline Jenis Data & $\begin{array}{l}\text { 1. Data Primer } \\
\text { 2. Data Sekunder }\end{array}$ \\
\hline $\begin{array}{l}\text { Metode Analisis } \\
\text { Data }\end{array}$ & $\begin{array}{l}\text { 1. Pengumpulan data } \\
\text { 2. Reduksi } \\
\text { 3. Penyajian }\end{array}$ \\
\hline
\end{tabular}




\begin{tabular}{|l|l|}
\hline $\begin{array}{l}\text { Metode Keabsahan } \\
\text { Data }\end{array}$ & Metode Triangulasi \\
\hline Kesimpulan & $\begin{array}{l}\text { Humas Pemda Provinsi Daerah Istimewa Yogyakarta sangat } \\
\text { berperan dalam media internal buletin Yogyakarta. Buletin } \\
\text { Jogjawara dapat dikonsumsi bagi khalayak eksternal karena isinya } \\
\text { bisa dipahami dan bermanfaat bagi masyarakat umum. Sehingga } \\
\text { hasil penelitan sesuai dengan teori yang digunakan, dilihat dalam } \\
\text { tugas dan tanggung jawab yang dikerjakan dengan baik. }\end{array}$ \\
\hline Saran & $\begin{array}{l}\text { Dalam pembagian Job deskripsi secara jabatan dan otoritas untuk } \\
\text { bisa lebih di spesifikasikan kembali, jangan sampai ada dualitas } \\
\text { tanggung jawab ataupun otoritas } \\
\text { Untuk para akademisi yang akan mengembangkan dan memodifikasi } \\
\text { penelitian ini disarankan variabel yang digunakan dalam penelitian } \\
\text { selanjutnya ditambah, jangan hanya peran. Melainkan adanya } \\
\text { kolerasi antar variabel. }\end{array}$ \\
\hline
\end{tabular}

\begin{tabular}{|l|l|}
\hline Judul Penelitian & $\begin{array}{l}\text { Peran Public Relations dalam implementasi Community } \\
\text { Development PT. TELKOM,Tbk Kandatel Yogyakarta }\end{array}$ \\
\hline Nama Peneliti & Aris Mazidah \\
\hline Universitas & Universitas Islam Negeri Sunan Kalijaga Yogyakarta \\
\hline Fakultas & Ilmu Sosial dan Humaniora \\
\hline Tahun & 2010 \\
\hline Rumusan Masalah & $\begin{array}{l}\text { 1. Bagaimana peran public relations dalam implementasi community } \\
\text { development PT.Telkom,Tbk Kandatel Yogyakarta? }\end{array}$ \\
\hline Tujuan Penelitian & $\begin{array}{l}\text { 1. Untuk Mengetahui program community development yang telah } \\
\text { dijalankan PT.Telkom,Tbk Kandatel Yogyakarta. } \\
\text { 2. Untuk mengetahui pelaksanaan program community development } \\
\text { yang telah dijalankan PT.Telkom,Tbk Kandatel Yogyakarta. } \\
\text { 3. Untuk mengetahui peran public relations PT.Telkom,Tbk } \\
\text { Kandatel Yogyakarta dalam kegiatan community development. }\end{array}$ \\
\hline Teori dan Konsep & $\begin{array}{l}\text { 1. Public Relations } \\
\text { a. Peran Public relations } \\
\text { b. fungsi dan tujuan Public relations } \\
\text { 2. Community Development } \\
\text { 3. Hubungan Public relations dengan Community Development }\end{array}$ \\
\hline Kualitatif \\
\hline Metode Penelitian
\end{tabular}




\begin{tabular}{|l|l|}
\hline & $\begin{array}{l}\text { Public relations sebagai teknisi komunikasi yang } \\
\text { mengkomunikasikan segala macam bentuk kegiatan dan } \\
\text { pelaksanaan program community development. }\end{array}$ \\
\hline Saran & $\begin{array}{l}\text { Public relations PT.Telkom Kandatel Yogyakarta hendaknya } \\
\text { berperan sesuai dengan job deskripsi yang sesuai dengan peran } \\
\text { Public relations yang sesungguhnya. Dan hendaknya memisahkan } \\
\text { antara bagian Public relations dengan sekertaris, karena kedua } \\
\text { bidang tersebut berbeda job desk namun ditangani oleh satu orang } \\
\text { yang merangkap dua jabatan sekaligus. }\end{array}$ \\
\hline
\end{tabular}

\begin{tabular}{|c|c|}
\hline Judul Penelitian & $\begin{array}{lrrrr}\text { PERANAN } & \text { HUMAS } & \text { PT. PLN } & \text { (PERSERO) } & \text { DISTRIBUSI } \\
\text { JAKARTA } & \text { RAYA } & \text { DAN } & \text { TANGERANG } & \text { DALAM } \\
\text { MEMANFAATKAN MEDIA DIGITAL } & & \end{array}$ \\
\hline Nama Peneliti & Fatimah Azahra \\
\hline Universitas & Universitas Sultan Ageng Tirtayasa Serang \\
\hline Fakultas & Ilmu sosial dan Ilmu politik \\
\hline Tahun & 2015 \\
\hline Rumusan Masalah & $\begin{array}{l}\text { 1. bagaimana peranan Humas PT.PLN (PERSERO) Distribusi } \\
\text { Jakarta Raya dan Tangerang dalam memanfaatkan media digital? }\end{array}$ \\
\hline Identifikasi Masalah & $\begin{array}{l}\text { 1. Bagaimana peranan Humas PT.PLN (PERSERO) Distribusi } \\
\text { Jakarta Raya dan Tangerang sebagai penasehat ahli dalam } \\
\text { memanfaatkan media digital? } \\
\text { 2. Bagaimana peranan Humas PT.PLN (PERSERO) Distribusi } \\
\text { Jakarta Raya dan Tangerang sebagai fasilitator komunikasi dalam } \\
\text { memanfaatkan media digital? } \\
\text { 3. Bagaimana peranan Humas PT.PLN (PERSERO) Distribusi } \\
\text { Jakarta Raya dan Tangerang sebagai praktisi pemecah masalah } \\
\text { dalam memanfaatkan media digital? } \\
\text { 4. Bagaimana peranan Humas PT.PLN (PERSERO) Distribusi } \\
\text { Jakarta Raya dan Tangerang sebagai teknisi komunikasi dalam } \\
\text { memanfaatkan media digital? }\end{array}$ \\
\hline Tujuan Penelitian & $\begin{array}{l}\text { 1. menjelaskan peranan Humas PT.PLN (PERSERO) Jakarta Raya } \\
\text { dan Tangerang sebagai penasehat ahli dalam memanfaatkan media } \\
\text { digital. } \\
\text { 2. menjelaskan peranan Humas PT.PLN (PERSERO) Jakarta Raya } \\
\text { dan Tangerang sebagai fasilitator komunikasi dalam memanfaatkan } \\
\text { media digital. } \\
\text { 3. menjelaskan peranan Humas PT.PLN (PERSERO) Jakarta Raya } \\
\text { dan Tangerang sebagai praktisi pemecah masalah dalam } \\
\text { memanfaatkan media digital. } \\
\text { 4. menjelaskan peranan Humas PT.PLN (PERSERO) Jakarta Raya } \\
\text { dan Tangerang sebagai teknisi komunikasi dalam memanfaatkan } \\
\text { media digital. }\end{array}$ \\
\hline Teori dan Konsep & $\begin{array}{l}\text { 1. Pengertian Komunikasi } \\
\text { 2. Humas } \\
\text { a. tugas utama humas } \\
\text { b. peranan humas } \\
\text { 3. Internet sebagai media komunikasi baru } \\
\text { 4. E-Public relations }\end{array}$ \\
\hline
\end{tabular}




\begin{tabular}{|c|c|}
\hline & $\begin{array}{l}\text { a. email } \\
\text { b. world Wide Web (www) } \\
\text { c. Virtual Communities } \\
\text { 5. Teori New Media } \\
\text { 6. Kerangka berpikir }\end{array}$ \\
\hline $\begin{array}{l}\text { Metodologi } \\
\text { Penelitian }\end{array}$ & Kualitatif Deskriptif \\
\hline Paradigma Penelitian & Paradigma Post Positivisime \\
\hline $\begin{array}{l}\text { Teknik Pengumpulan } \\
\text { Data }\end{array}$ & Metode wawancara, observasi dan studi pustakaan \\
\hline Analisis Data & $\begin{array}{l}\text { Inventaris data, kategorisasi data, penafsiran data dan penarikan } \\
\text { kesimpulan }\end{array}$ \\
\hline Uji validitas data & Triangulasi \\
\hline Kesimpulan & $\begin{array}{l}\text { 1. sebagai penasehat ahli humas PT.PLN (PERSERO) Disitribusi } \\
\text { Jakarta Raya dan Tangerang menjalankan perannya dengan } \\
\text { memberikan nasehat berdasarkan kasus atau kejadian yang terjadi } \\
\text { sebelumnya. Sehingga humas mempunyai landasan dalam } \\
\text { memberikan nasehat. } \\
\text { 2. sebagai fasilitator komunikasi Humas PT.PLN (PERSERO) } \\
\text { Distribusi Jakarta Raya dan Tangerang bertindak sebagai pemberi } \\
\text { informasi yang berhubungan dengan perusahaan.eamil dan tv } \\
\text { internal digunakan untuk melakukan koordinasi, menyebarkan } \\
\text { informasi yang berkaitan dengan perusahaan serta melakukan media } \\
\text { monitoring. } \\
\text { 3. sebagai praktisi pemecah masalah Humas PT.PLN (PERSERO) } \\
\text { Distribusi Jakarta Raya dan Tangerang adalah dengan berhubungan } \\
\text { langsung dengan contact center 123. Karena merupakan wadah } \\
\text { pertama untuk menampung semua keluhan pelanggan PLN } \\
\text { 4. sebagai teknisi komunikasi Humas PT.PLN (PERSERO) } \\
\text { Distribusi Jakarta Raya dan Tangerang dengan bergabung pada milis } \\
\text { wartawan rubric energy dibawah naungan kementrian ESDM. } \\
\text { Humas juga bergabung dalam forum online terbesar di Indonesia } \\
\text { yaitu kaskus }\end{array}$ \\
\hline Saran & $\begin{array}{l}\text { Diharapkan adanya tindak lanjut dalam memanfaatkan media digital. } \\
\text { Tidak hanya dalam bentuk sosialisasi ataupun edukasi. Dan tidak ada } \\
\text { salahnya membuat media internal lain untuk menyebarkan informasi } \\
\text { di wilayah internal perusahaan, tidak hanya TV internal saja, } \\
\text { sehingga informasi semakin tersebar ke seluruh area atau seluruh } \\
\text { divisi perusahaan. }\end{array}$ \\
\hline
\end{tabular}

\begin{tabular}{|l|l|}
\hline Judul Penelitian & $\begin{array}{l}\text { PERAN HUMAS DALAM RANGKA MENINGKATKAN CITRA } \\
\text { SEKOLAH DI SMK YPKK 3 SLEMAN YOGYAKARTA }\end{array}$ \\
\hline Nama Peneliti & Ira Dwi Rahayu \\
\hline Universitas & Universitas Negeri Yogyakarta \\
\hline Fakultas & Ekonomi \\
\hline Tahun & 2014 \\
\hline Identifikasi Masalah & $\begin{array}{l}\text { 1. masyarakat belum mengetahui banyak tentang SMK YPKK 3 } \\
\text { Sleman Yogyakarta. }\end{array}$ \\
\hline
\end{tabular}




\begin{tabular}{|c|c|}
\hline & $\begin{array}{l}\text { 2. Masyarakat belum mengetahui potensi yang ada di SMK YPKK } 3 \\
\text { Sleman Yogyakarta. } \\
\text { 3. kegiatan sosialisasi yang dilakukan oleh SMK YPKK } 3 \text { Sleman } \\
\text { Yogyakarta belum menyeluruh pada masyarakat. }\end{array}$ \\
\hline Batasan Masalah & $\begin{array}{l}\text { Fokus pada peran kehumasan dalam rangka meningkatkan citra } \\
\text { sekolah. }\end{array}$ \\
\hline Rumusan Masalah & $\begin{array}{l}\text { 1. bagaimana peran kehumasan dalam upaya meningkatkan citra } \\
\text { sekolah di SMK YPKK } 3 \text { Sleman Yogyakarta? }\end{array}$ \\
\hline Tujuan Penelitian & $\begin{array}{l}\text { 1. untuk mengetahui peran kehumasan dalam rangka meningkatkan } \\
\text { citra sekolah di SMK YPKK } 3 \text { Sleman Yogyakarta. }\end{array}$ \\
\hline Teori dan Konsep & $\begin{array}{l}\text { 1. Humas } \\
\text { a. Pengertian hubungan masyarakat } \\
\text { b. Peran dan tujuan Hubungan Masyarakat } \\
\text { c. Tugas Hubungan Masyarakat } \\
\text { d. Hambatan Hubungan Masyarakat } \\
\text { e. Bentuk Hubungan Masyarakat } \\
\text { f. Proses Hubungan Masyarakat } \\
\text { g. Media Hubungan Masyarakat } \\
\text { h. Publik dalam public relations } \\
\text { i. Peran Humas dalam rangka membangun citra positif sekolah } \\
\text { 2. Komunikasi } \\
\text { a. Definisi Komunikasi } \\
\text { b. Komponen Komunikasi } \\
\text { c. Komunikasi dalam lembaga pendidikan } \\
\text { d. Public relations sebagai teknik komunikasi } \\
\text { 3. Citra } \\
\text { a. pengertian Citra } \\
\text { b. Proses Pembentukan Citra } \\
\text { c. Citra Organisasi }\end{array}$ \\
\hline Metode Penelitian & Kualitatif Deskriptif \\
\hline Subjek Penelitian & Wakasek Kehumasan \\
\hline $\begin{array}{l}\text { Teknik Pengumpulan } \\
\text { Data }\end{array}$ & Wawancara, Dokumentasi (kalender, poster dan booklet) \\
\hline Teknik Analisis Data & $\begin{array}{l}\text { Data hasil wawancara, observasi dan dokumentasi yang sudah } \\
\text { terkumpul direduki. }\end{array}$ \\
\hline $\begin{array}{l}\text { Teknik Keabsahan } \\
\text { Data }\end{array}$ & Triangulasi \\
\hline Kesimpulan & $\begin{array}{l}\text { Berdasarkan deskripsi, analisis dan pembahasan data maka dapat } \\
\text { ditarik kesimpulan bahwa dengan dilaksanakannya peran kehumasan } \\
\text { dalam rangka meningkatkan citra sekolah di SMK YPKK } 3 \text { Sleman } \\
\text { Yogyakarta belum memperoleh hasil yang baik, hal tersebut dilihat } \\
\text { dari jumlah murid yang mendaftar ke SMK YPKK } 2 \text { Sleman } \\
\text { Yogyakarta masih kurang dari target yang ditentukan oleh sekolah. }\end{array}$ \\
\hline Saran & $\begin{array}{l}\text { SMK YPKK } 3 \text { Sleman Yogyakarta sebaiknya memfungsikan } \\
\text { website yang telah dibuat dan selalu meng-update informasinya } \\
\text { sebagai media sosialisasi dan informasi kepada publiknya. Dan } \\
\text { meminimalisir kendala-kendala yang menjadi faktor kegagalan } \\
\text { dalam menjalankan peran humas. }\end{array}$ \\
\hline
\end{tabular}




\begin{tabular}{|c|c|}
\hline Judul Penelitian & $\begin{array}{lcccr}\text { PERANAN } & \text { HUMAS } & \text { DALAM } & \text { MENINGKATKAN } & \text { CITRA } \\
\text { RUMAH } & \text { SAKIT } & \text { KUSTA } & \text { DR.TADJUDDIN } & \text { CHALID } \\
\text { MAKASSAR } & & & \\
\end{array}$ \\
\hline Nama Peneliti & Fikhi Handayani \\
\hline Universitas & Universitas Hasanudin \\
\hline Fakultas & Ilmu sosial dan Ilmu politik \\
\hline Tahun & 2015 \\
\hline Rumusan Masalah & $\begin{array}{l}\text { 1. Bagaimana peran Humas Rumah Sakit Dr.Tadjuddin Chalid } \\
\text { Makassar dalam menjalankan fungsinya untuk meningkatkan citra } \\
\text { instansi? } \\
\text { 2. Bagaimana aktivitas-aktivitas Humas Rumah Sakit Dr.Tadjuddin } \\
\text { Chalid Makassar dalam menjalankan fungsinya untuk meningkatkan } \\
\text { citra instansi? }\end{array}$ \\
\hline Tujuan Penelitian & $\begin{array}{l}\text { 1. Untuk mengetahui peranan Humas Rumah Sakit Dr.Tadjuddin } \\
\text { Chalid Makassar dalam menjalankan fungsinya untuk meningkatkan } \\
\text { citra instansi. } \\
\text { 2. Untuk menguraikan aktivitas-aktivitas yang dilakukan oleh } \\
\text { Humas Rumah Sakit Dr.Tadjuddin Chalid Makassar dalam } \\
\text { menjalankan fungsinya untuk meningkatkan citra instansi. }\end{array}$ \\
\hline Metode Penelitian & Deskriptif Kualitatif \\
\hline Teknik Pengumpulan & 1. Data Primer (observarsi dan wawancara) \\
\hline Data & $\begin{array}{l}\text { 2. Data Sekunder (literatur, karangan ilmiah, dan pendapat para ahli } \\
\text { yang mendukung penelitian ini). }\end{array}$ \\
\hline Teknik Analisi Data & Analisis Deskriptif Kualitatif \\
\hline Teori dan Konsep & $\begin{array}{l}\text { 1. Peran } \\
\text { 2. Stigma } \\
\text { 3. Humas } \\
\text { a. Definisi public relations (Humas) } \\
\text { b. Peranan Humas } \\
\text { c. Ruang Lingkup Humas } \\
\text { d. Tujuan Humas } \\
\text { e. Fungsi Humas } \\
\text { d. Tugas Humas } \\
\text { 4. Citra }\end{array}$ \\
\hline Kesimpulan & $\begin{array}{l}\text { Hasil penelitian menunjukkan bahwa praktisi humas Dr.Tadjuddin } \\
\text { Chalid Makassar menjalankan keempat kategori peran sesuai konsep } \\
\text { Dozier \& Broom, yaitu sebagai penasehat ahli, fasilitator } \\
\text { komunikasi, fasilitator proses pemecah masalah dan teknisi } \\
\text { komunikasi. }\end{array}$ \\
\hline Saran & $\begin{array}{l}\text { Sebaiknya praktisi humas lebih membangun dan membina hubungan } \\
\text { dengan media, seperti melakukan media visit atau konferensi pers, } \\
\text { menambah sumber daya manusia di bidang humas dan } \\
\text { meningkatkan kegiatan CSR sehingga bisa lebih mempererat ikatan } \\
\text { emosional instansi dengan masyarakat termasuk pasien. }\end{array}$ \\
\hline
\end{tabular}

\begin{tabular}{|l|llllr|}
\hline Judul Penelitian & PERANAN HUMAS & PEMDA & SRAGEN & DALAM \\
& MENINGKATKAN CITRA & LEMBAGA (Studi Deskriptif \\
& Kualitatif mengenai & peranan & Humas & PEMDA Sragen dalam \\
& meningkatkan citra lembaga melalui program Car Free Day) \\
\hline
\end{tabular}




\begin{tabular}{|c|c|}
\hline Nama Peneliti & Anang Wibowo \\
\hline Universitas & Universitas Muhammadiyah Surakarta \\
\hline Fakultas & Komunikasi dan Informatika \\
\hline Tahun & 2013 \\
\hline Rumusan Masalah & $\begin{array}{l}\text { Bagaimana peranan humas PEMDA Sragen dalam meningkatkan } \\
\text { citra lembaga melalui program Car Free Day (CFD)? }\end{array}$ \\
\hline Tujuan Penelitian & $\begin{array}{l}\text { Untuk mengetahui peranan humas PEMDA Sragen dalam } \\
\text { meningkatkan citra lembaga melalui program Car Free Day (CFD). }\end{array}$ \\
\hline Teori dan Konsep & $\begin{array}{l}\text { 1. pengertian komunikasi } \\
\text { 2. public relations } \\
\text { 3. konsep spesial event } \\
\text { 4. pengertian citra }\end{array}$ \\
\hline $\begin{array}{l}\text { Metodologi } \\
\text { Penelitian }\end{array}$ & Deskriptif Kualitatif \\
\hline $\begin{array}{l}\text { Teknik Pengumpulan } \\
\text { Data }\end{array}$ & Purposive Non Random Sampling \\
\hline Sumber Data & $\begin{array}{l}\text { Data primer (wawancara) dan Data sekunder observasi dan } \\
\text { dokumentasi berupa gambar dan literatur. }\end{array}$ \\
\hline Teknik Analisis Data & Analisis Interaktif \\
\hline Keabsahan Data & Triangulasi \\
\hline Kesimpulan & $\begin{array}{l}\text { Kegiatan car free day (CFD) yang dilakukan oleh pemerintah } \\
\text { Kabupaten Sragen dapat meningkatkan citra positif Pemerintah } \\
\text { Daerah Kabupaten Sragen dan hingga saat ini kegiatan tersebut terus } \\
\text { berjalan yang membuktikan program car free day berhasil sesuai } \\
\text { dengan tujuan awal dari Pemerintah Kabupaten Sragen. }\end{array}$ \\
\hline
\end{tabular}

\begin{tabular}{|l|l|}
\hline Judul Penelitian & $\begin{array}{l}\text { PERAN HUMAS DALAM RANGKA MEMBANGUN CITRA } \\
\text { DAN MEMPROMOSIKAN SMK PGRI 1 SENTOLO KULON } \\
\text { PROGO }\end{array}$ \\
\hline Nama Peneliti & Esty Cahyaningsih \\
\hline Universitas & Universitas Negeri Yogyakarta \\
\hline Fakultas & Ekonomi \\
\hline Tahun & 2015 \\
\hline Rumusan Masalah & $\begin{array}{l}\text { 1. Bagaimana peran humas dalam rangka membangun citra SMK } \\
\text { PGRI 1 Sentelo dan bagaimana upaya dalam mempromosikan SMK } \\
\text { PGRI Sentolo? } \\
\text { 2. Media apa saja yang digunakan humas dalam membangun citra } \\
\text { SMK PGRI 1 Sentolo dan mempromosikan SMK PGRI 1 Sentolo? } \\
\text { 3. Apa sajakah kendala atau hambatan yang ditemui dalam rangka } \\
\text { membangun citra dan mempromosikan SMK PGRI 1 Sentolo? } \\
\text { 4. Apakah solusi yang ditempuh guna mengatasi kendala atau } \\
\text { hambatan yang ditemui dalam membangun citra dan } \\
\text { mempromosikan SMK PGRI 1 Sentolo? }\end{array}$ \\
\hline Tujuan Penelitian & $\begin{array}{l}\text { 1. Mengetahui bagaimanakah peran humas dalam rangka } \\
\text { membangun citra SMK PGRI 1 Sentolo dan cara yang ditempuh } \\
\text { dalam mempromosikan SMK PGRI Sentolo. } \\
\text { 2. Mengetahui media apa saja yang digunakan humas dalam } \\
\text { membangun citra SMK PGRI 1 Sentolo dan mempromosikan SMK } \\
\text { PGRI Sentolo. }\end{array}$ \\
\hline
\end{tabular}




\begin{tabular}{|c|c|}
\hline & $\begin{array}{l}\text { 3. Mengetahui berbagai kendala atau hambatan yang ditemui dalam } \\
\text { rangka membangun citra dan mempromosikan SMK PGRI } 1 \\
\text { Sentolo. } \\
\text { 4. Mengetahui solusi yang ditempuh guna mengatasi kendala atau } \\
\text { hambatan yang ditemui dalam membangun citra dan } \\
\text { mempromosikan SMK PGRI } 1 \text { Sentolo. }\end{array}$ \\
\hline Metode Penelitian & Deskriptif Kualitatif \\
\hline $\begin{array}{l}\text { Teknik Pengumpulan } \\
\text { Data }\end{array}$ & Observasi, wawancara dan dokumentasi. \\
\hline Teknik Analisis Data & Analisis Interaktif \\
\hline Keabsahan Data & Triangulasi sumber dan data \\
\hline Teori dan Konsep & $\begin{array}{l}\text { 1.Hubungan Masyarakat (Humas) } \\
\text { a. Pengertian Humas } \\
\text { b. Peran dan Tujuan Humas } \\
\text { c. Fungsi Humas } \\
\text { d. Bentuk Humas } \\
\text { e. Sasaran/ Khalayak Humas } \\
\text { f. Media Humas } \\
\text { 2. Komunikasi } \\
\text { a. Pengertian Komunikasi } \\
\text { b. Komponen Komunikasi } \\
\text { c. Komunikasi public relations } \\
\text { 3. Citra } \\
\text { a. Pengertian Citra } \\
\text { b. Macam-macam Citra } \\
\text { 4. Pentingnya hubungan sekolah dengan masyarakat dan pentingnya } \\
\text { peran masyarakat bagi sekolah. } \\
\text { 5. Promosi } \\
\text { a. Pengertian Promosi } \\
\text { b. Promosi Pendidikan } \\
\text { c. Strategi Promosi di Lembaga Pendidikan }\end{array}$ \\
\hline Kesimpulan & $\begin{array}{l}\text { Peran humas secara keseluruhan belum berjalan secara baik, seperti } \\
\text { : peran humas sebagai komunikator terhadap publik internal dan } \\
\text { ekternal, peran humas sebagai pembina hubungan dan juga peran } \\
\text { humas dalam membangun citra. }\end{array}$ \\
\hline Saran & $\begin{array}{l}\text { Sebaiknya dalam penggunaan media komunikasi humas dengan } \\
\text { publik internal perlu ditambahkan berupa penempelan surat kabar } \\
\text { setiap harinya, pembaharuan mading sekolah setidaknya } 1 \text { bulan } 1 \\
\text { kali. Dalam pemanfaatan website sekolah sebaiknya harus lengkap } \\
\text { dan jelas serta selalu diperbaharui agar publik eksternal mengetahui. }\end{array}$ \\
\hline
\end{tabular}

\begin{tabular}{|l|l|}
\hline Judul Penelitian & $\begin{array}{l}\text { PERAN HUMAS DALAM MENINGKATKAN PELAYANAN } \\
\text { INFORMASI BPJS KESEHATAN MAKASSAR }\end{array}$ \\
\hline Nama Peneliti & Nurfair \\
\hline Universitas & Universitas Hassanudin Makassar \\
\hline Fakultas & Ilmu sosial dan Ilmu politik \\
\hline Tahun & 2017 \\
\hline
\end{tabular}




\begin{tabular}{|c|c|}
\hline Rumusan Masalah & $\begin{array}{l}\text { 1. Bagaimana peran Humas BPJS Kesehatan Makassar dalam } \\
\text { meningkatkan pelayanan informasi mengenai program Jaminan } \\
\text { kesehatan? } \\
\text { 2. Bagaimana upaya Humas BPJS Kesehatan Makassar dalam } \\
\text { menghadapi masalah meningkatkan pelayanan informasi mengenai } \\
\text { program Jaminan kesehatan? }\end{array}$ \\
\hline Tujuan Penelitian & $\begin{array}{l}\text { 1. Untuk mengetahui peran Humas BPJS Kesehatan Makassar dalam } \\
\text { meningkatkan pelayanan informasi mengenai program Jaminan } \\
\text { kesehatan. } \\
\text { 2. Untuk mengetahui upaya Humas BPJS Kesehatan Makassar } \\
\text { dalam menghadapi masalah meningkatkan pelayanan informasi } \\
\text { mengenai program Jaminan kesehatan. }\end{array}$ \\
\hline Metode Penelitian & Deskriptif Kualitatif \\
\hline $\begin{array}{l}\text { Teknik Pengumpulan } \\
\text { Data }\end{array}$ & $\begin{array}{l}\text { Data Primer ( Observasi dan wawancara) } \\
\text { Data Sekunder (literatur yang relevan seperti buku, jurnal, skripsi, } \\
\text { surat kabar dan internet. }\end{array}$ \\
\hline Anal & $\begin{array}{l}\text { Pengumpulan data, reduksi data, penyajian data dan penarikan } \\
\text { kesimpulan. }\end{array}$ \\
\hline Konsep & $\begin{array}{l}\text { 1. Pengertian Humas } \\
\text { 2. Ruang Lingkup Humas } \\
\text { 3. Peran Humas } \\
\text { 4. Pelayanan }\end{array}$ \\
\hline Kes & $\begin{array}{l}\text { BPJS Kesehatan Makassar telah melaksanakan peran humas sesuai } \\
\text { peran humas yang diungkap oleh Dozier dan Bromm. Upaya humas } \\
\text { menghadapi masalah pelayanan informasi mengenai program } \\
\text { jaminan kesehatan yaitu menentukan masalah terlebih dahulu } \\
\text { selanjutnya melakukan perencanaan dan penyusunan program atau } \\
\text { strategi untuk mengatasi masalah yang ada. Dan terakhir melakukan } \\
\text { evaluasi. }\end{array}$ \\
\hline Saran & $\begin{array}{l}\text { Seharusnya peran praktisi humas BPJS Kesehatan Makassar sebagai } \\
\text { penasehat ahli lebih ditingkatkan dengan cara mengikuti praktisi } \\
\text { humas pada pelatihan-pelatihan kehumasan dan lebih sering } \\
\text { melibatkan praktisi humas ketika sedang menghadapi sebuah } \\
\text { permasalahan. Dan sebaiknya BPJS Kesehatan Makassar memiliki } \\
\text { akun media sosial sendiri agar masyarakat khususnya kota makassar } \\
\text { lebih mudah mendapatkan informasi terupdate mengenai BPJS } \\
\text { Kesehatan cabang Makassar. }\end{array}$ \\
\hline
\end{tabular}

